\title{
Diffuse Neuromatosis of Intrahepatic and Extrahepatic Bile Ducts as a Rare Cause of Jaundice
}

\author{
Nikolaos Vassos ${ }^{\mathrm{a}, \mathrm{b}}$ Aristotelis Perrakis ${ }^{\mathrm{c}}$ Axel Schmid $^{\mathrm{d}}$ Roland S. Croner ${ }^{\mathrm{c}}$ \\ Robert Gruetzmann ${ }^{\mathrm{a}}$ Abbas Agaimy ${ }^{\mathrm{e}}$ \\ ${ }^{a}$ Department of Surgery, University Hospital Erlangen, Erlangen, Germany; ${ }^{b}$ Division of Surgical Oncology \\ and Thoracic Surgery, Department of Surgery, Mannheim University Medical Centre, University of Heidelberg, \\ Mannheim, Germany; ${ }^{C}$ Department of Surgery, University Hospital Magdeburg, Magdeburg, Germany; ${ }^{\mathrm{d}}$ Department \\ of Radiology, University Hospital Erlangen, Erlangen, Germany; ${ }^{\text {}}$ Department of Pathology, University Hospital \\ Erlangen, Erlangen, Germany
}

\section{Keywords}

Bile duct neuroma - Bile duct stenosis - Jaundice .

Neuromatosis $\cdot$ Cholangiocarcinoma included in the differential diagnosis of bile duct neoplasms, in particular when there is a previous surgical history in this abdominal region.

๑) 2020 S. Karger AG, Basel

\begin{abstract}
Background: Neuroma of the biliary tree is extremely rare with no more than 100 cases reported so far. They mostly present with obstructive jaundice and have been commonly described after surgery or abdominal trauma. Although involvement of the extrahepatic bile duct is far more common, occurrence in the intrahepatic ducts has not so far been reported. Case Report: We describe 3 cases of diffuse biliary tree neuroma affecting 3 females aged 53-68 years. None had a history of neurofibromatosis type1. All presented with progressive obstructive jaundice with no evidence of gallstones. A history of previous surgery was noted in 2 patients. Initial impression on clinical and imaging examination was highly suspicious for bile duct carcinoma in 2 patients. Histology showed diffuse neuromatous proliferation replacing and thickening the bile duct walls. The third patient had concurrent neuroma and recurrent cholangiocarcinoma causing great clinical confusion as initial biopsy showed only benign neuroma, but CA 19-9 was steadily increasing, necessitating a second biopsy which then confirmed recurrent carcinoma. Conclusion: This uncommon cause of long-distance bile duct stenosis and progressive jaundice should be
\end{abstract}

\section{Introduction}

Benign tumors of the biliary tree are rare. They include adenomas, carcinoid tumors, and tumors of the supporting connective tissue structures such as granular cell tumors, leiomyomas, lipomas, neurofibromas, schwannomas, or neuromas [1]. Neuromas arising in the biliary tree are rare, with approximately 100 cases reported in the English literature so far [2-4]. They are mostly localized in the extrahepatic bile duct due to the abundant anastomotic network of sympathetic and parasympathetic nerve fibers and small nerves accompanying blood vessels from branches of the hepatic and gastroduodenal arteries [5]. They mostly present with obstructive jaundice and are almost indistinguishable from malignant tumors before surgery and thus need to be resected.

We present the preoperative imaging, operative management, and histopathological diagnosis of 3 cases of bile tree neuromas and discuss their clinicopathological features together with a review of literature on this rare condition. 
Fig. 1. ERC showing complete occlusion of the common hepatic duct (a), treated by stenting of the left hepatic duct (b).
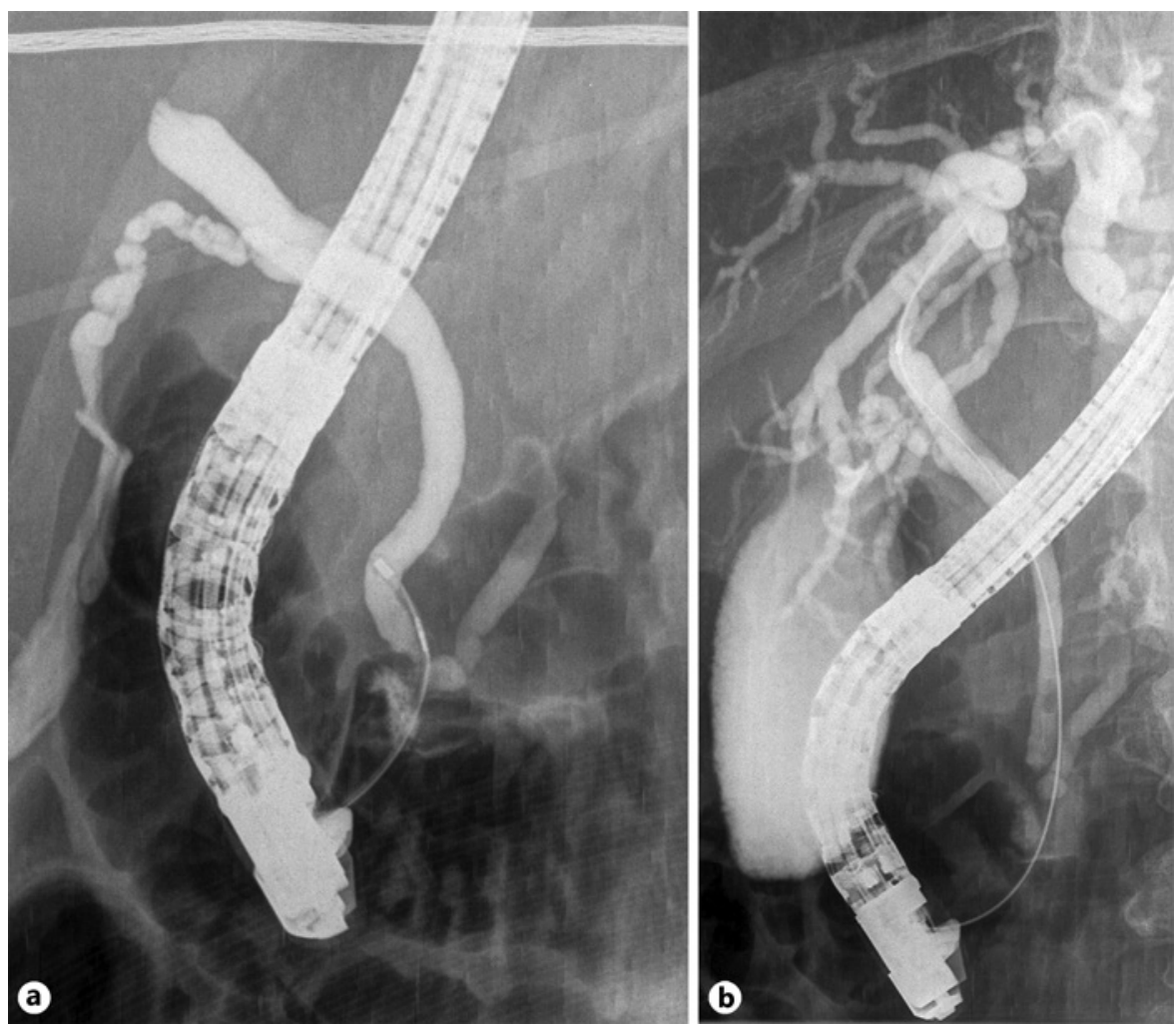

\section{Case Series Presentation}

Case 1

A 53-year-old female was admitted to the department of gastroenterology of a regional hospital with progressive jaundice for 2 months. She had no history of general fatigue, fever, abdominal pain, or weight loss. Her past medical history was significant for arterial hypertension and her past surgical history was not remarkable. Upon admission, the vital signs were unremarkable, and the patient was in good physical condition. Abdominal examination revealed no organomegaly. The total bilirubin level was $4,22 \mathrm{mg} /$ dL (direct: 3,97). Her liver enzyme tests were as follows: GOT 395 U/l, GPT 552 U/L, gamma-GT 910 U/L (normal <60). Viral hepatitis serology (HBsAg, anti-HBs IgM, anti-HAV IgM, and HCV RNA) was negative. The tumor marker serum CA 19-9 was 2,252 $\mathrm{U} / \mathrm{mL}$ (normal $<27$ ). The CEA and CA $72-4$ were normal.

Abdominal ultrasound showed dilatation of the intrahepatic (both lobes) and the proximal extrahepatic bile ducts. The distal common bile duct was normal, the gallbladder was free of stones, and there was no mass in the pancreatic head. Endoscopic retrograde cholangiopancreatography (ERCP) demonstrated a stricture at the hepatic duct bifurcation. Cholangiocarcinoma (Klatskin tumor stage III) was suspected, but brushings for cytology were negative for malignancy. After endoscopic sphincterotomy of the bile duct, a biliary stent $(14 \mathrm{~cm}, 8.5$ French) was passed above the lesion into the left hepatic duct to relieve the biliary obstruction (Fig. 1). Magnetic resonance imaging (MRI) showed a branching solid mass along the proximal common hepatic duct extending beyond the biliary confluence with dilatation of the right intrahepatic bile ducts (Fig. 2). Pancreatic ducts, middle, and lower thirds of the extrahepatic bile duct were normal, and there were no metastatic lesions. Magnetic resonance cholangiopancreatography (MRCP) confirmed these findings. In the course of the next days, the patient developed symptomatic cholangitis, for which she re-

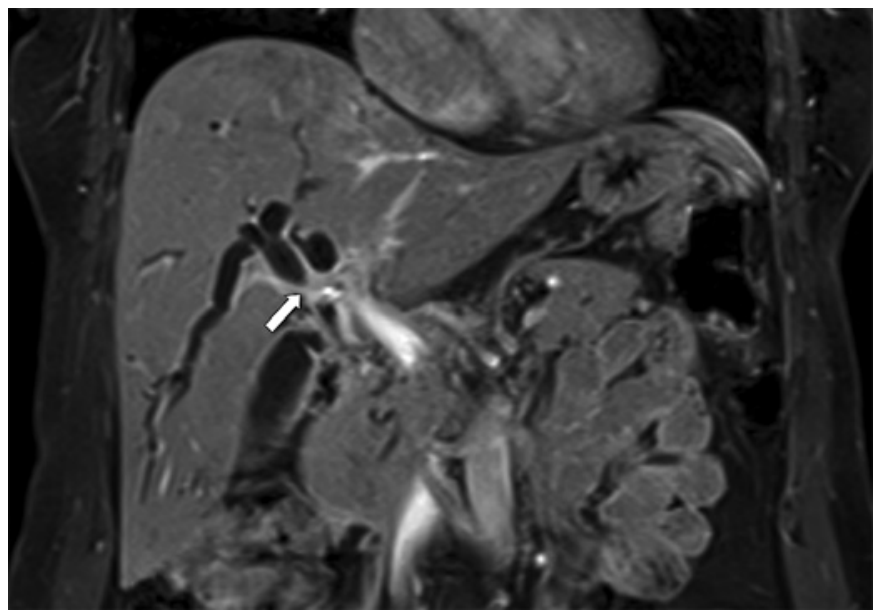

Fig. 2. Contrast-enhanced T1-weighted SE imaging documenting a small mass obstructing the common hepatic duct bifurcation at the level of the liver surface.

ceived antibiotic therapy (meropenem), and a new ERCP was performed. The biliary stent was removed, and the known stricture in the left hepatic duct was stretched using a bougie $(5 / 8.5 \mathrm{~F})$ but it could not be overcome, and a nasobiliary drain was inserted in the right hepatic duct. The radiologic control showed a right position of the drain and a good flow of the contrast agent.

After the symptoms resolved, an explorative laparoscopy and laparotomy were performed. At surgery, the bifurcation of the right and left hepatic duct was infiltrated and obliterated by a diffuse firm mass that did not invade adjacent organs. The obstructed segment (right hepatic duct, left hepatic duct, small bile 

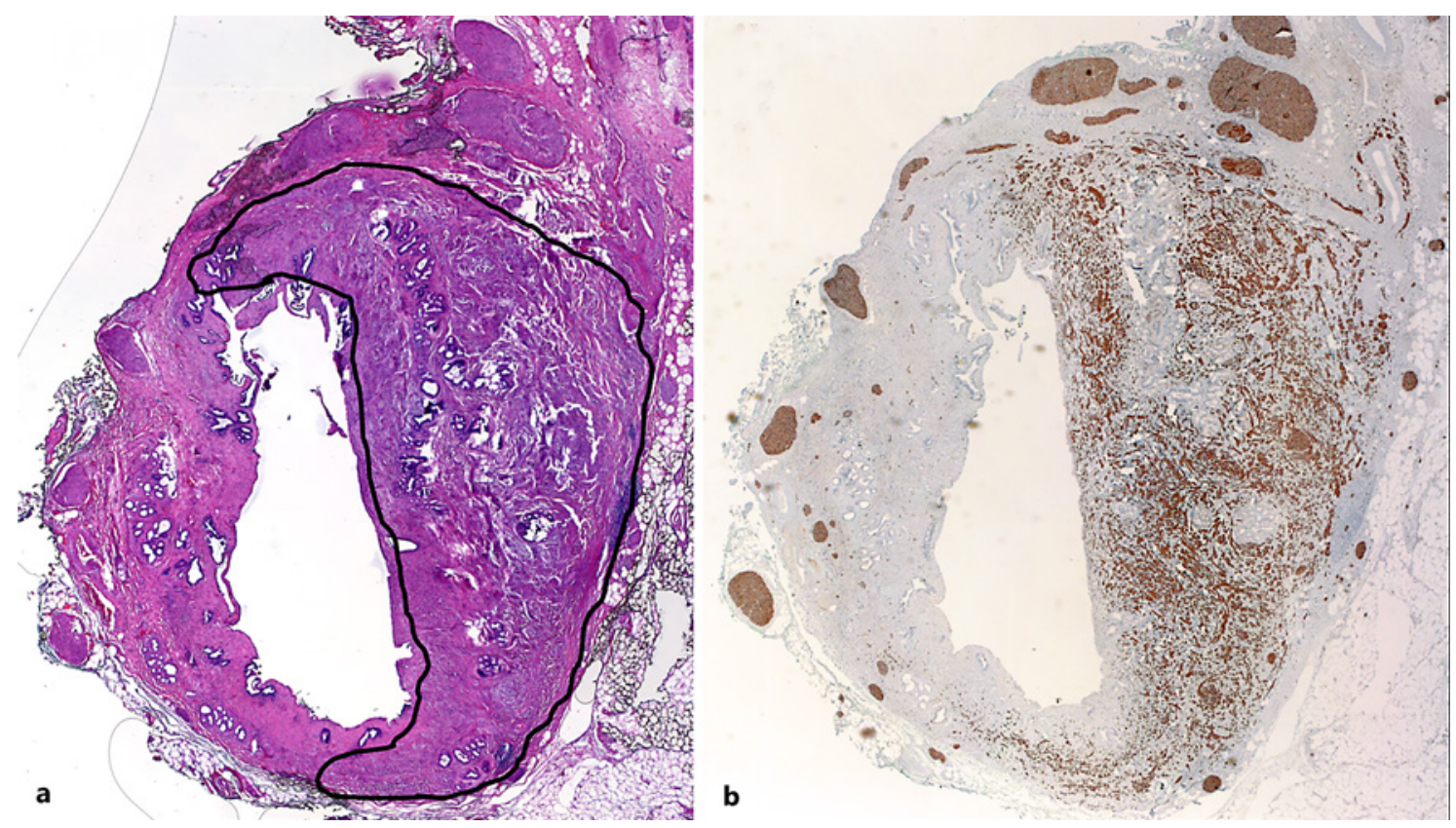

Fig. 3. a Overview (H\&E stain) showing diffuse bile duct wall thickening; note hypertrophied nerve bundles on top of the thickening and on the left side. $\mathbf{b}$ The same lesion is highlighted by S-100 protein immunostaining.

duct of liver segment I, and proximal common bile duct) was resected along with the gallbladder and periportal lymphadenectomy. The right hepatic duct, the left hepatic duct and the small bile duct of the segment I were anastomosed with a bowel loop (biliodigestive anastomosis/hepaticojejunostomy) according to the Roux-en-Y method. The distal part of the extrahepatic bile duct was oversutured. At the time of surgery, a frozen-section examination could not differentiate the process as a benign versus malignant lesion.

Pathological examination showed diffuse neural hyperplasia replacing and thickening the wall of the bile ducts, with the presence of adjacent numerous severely thickened hypertrophied and branched nerve bundles (Fig. 3). Ganglion cells were not observed. The resection margins were free, and five lymph nodes were also free of tumor. These findings were consistent with a diffuse neuroma/-tosis of the bile duct.

The patient was discharged home on day 10 after an unremarkable hospital course. Currently, after 42 months of follow-up, she is doing well, without evidence of recurrent disease.

\section{Case 2}

A 68-year-old female with cholecystectomy performed at the age of 53 years presented with progressive jaundice. Esophagogastroduodenoscopy showed no abnormalities. ERCP demonstrated a 14-mm long high-grade (>90\%) stricture of the proximal common hepatic duct, $2 \mathrm{~cm}$ from the hepatic duct bifurcation. This stricture was expanded with bougies (till 11.5 French), and a biliary stent $(14 \mathrm{~cm}, 12.0$ French) was placed into the common hepatic duct. Biopsies were negative for malignancy. Computed tomography (CT) showed no pancreatobiliary mass or metastatic hepatic and peritoneal lesions. The patient regularly received a therapeutic ERCP with replacement of the stent for a period of 2 years, in which the imaging via CT showed a solid mass surrounding the portal vein and the main hepatic duct in the liver hilum (Fig. 4). The inflammation values and tumor markers were normal. Due to a progressive abdominal pain, explorative laparotomy was indi-

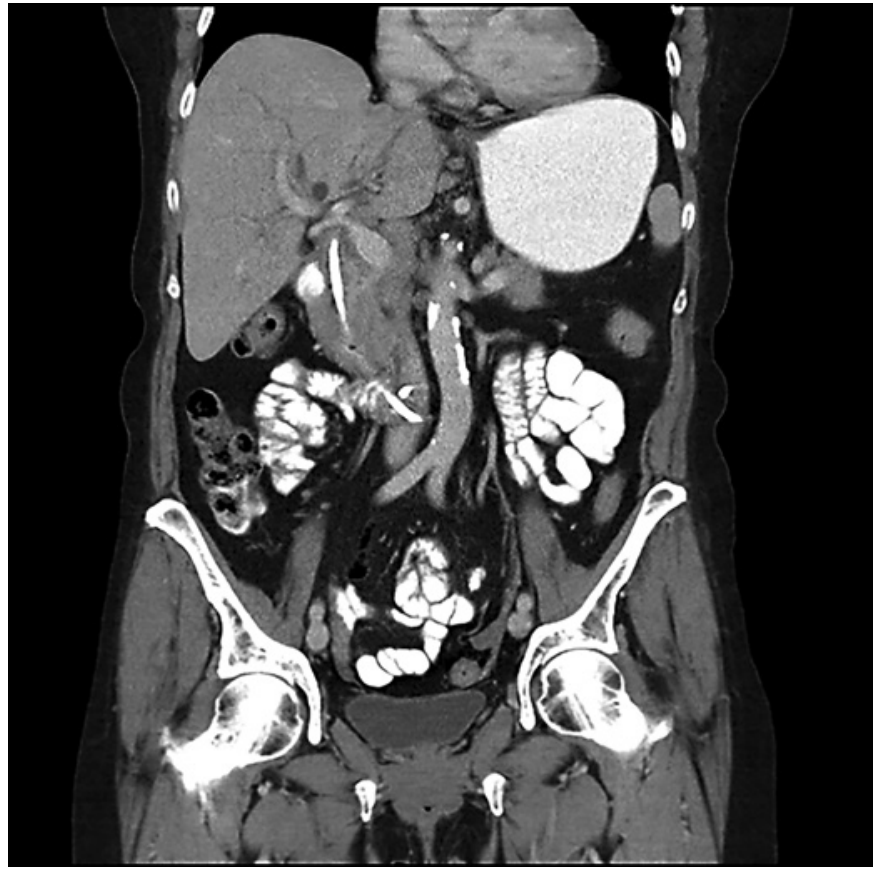

Fig. 4. CT showing a solid tissue surrounding the main hepatic duct, where a bile duct stent was already located.

cated. A 3-cm long stricture of the common bile duct was resected, and a biliodigestive anastomosis performed. A frozen-section examination at the time of surgery revealed no malignancy. The postoperative pathological findings were identical to case 1, and the resection margins were free of disease. After 66 months of followup, the patient is alive without any evidence of disease. 


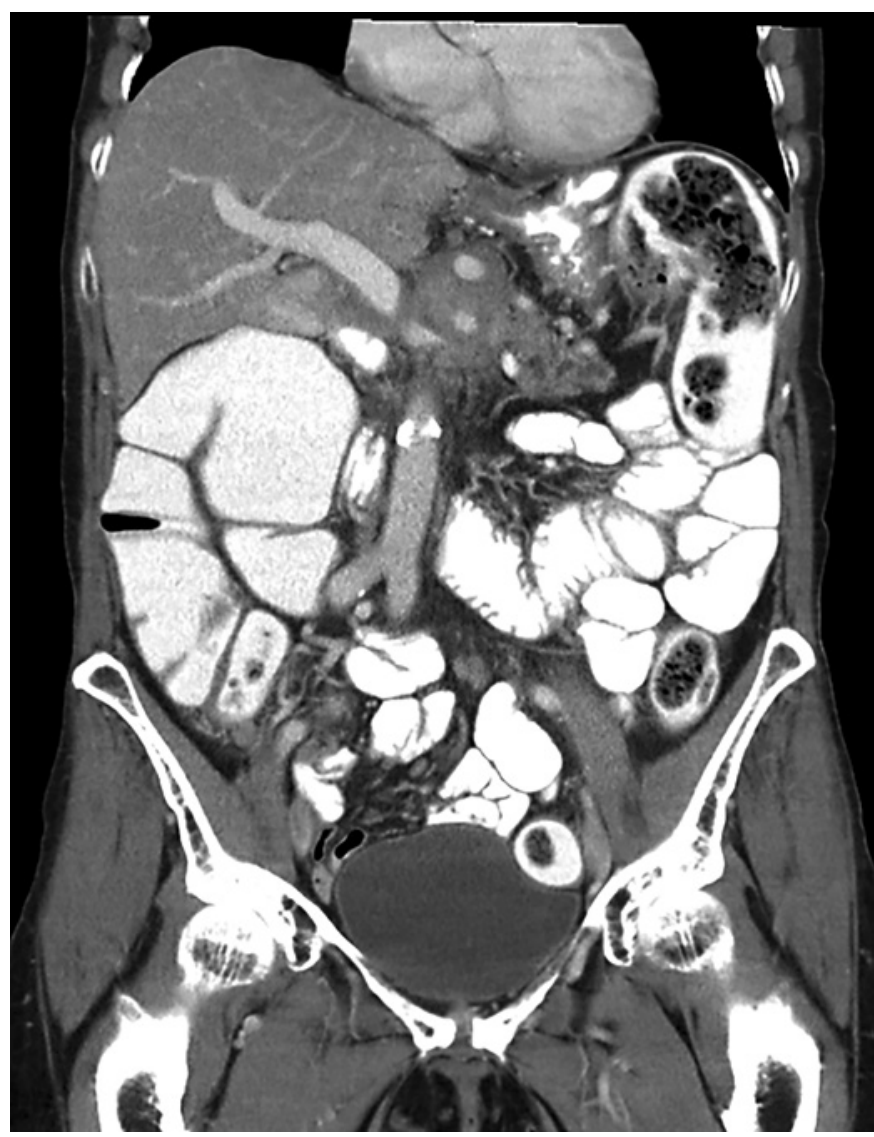

Fig. 5. CT showing a suspicious solid pancreatic mass surrounding the superior mesenteric artery and vein, and the celiac artery.

\section{Case 3}

A 68-year-old female underwent whipple operation for cholangiocarcinoma (pT2, pN1, cM0, G2) followed by adjuvant chemotherapy for 6 months. Eighteen months later, CT showed a suspicious $(3.5 \times 3.0 \mathrm{~cm})$ lesion around the superior mesenteric artery without evidence of metastases. CA 19-9 was $84 \mathrm{U} / \mathrm{ml}$ (normal $<5)$. A CT-guided biopsy of the mass showed a traumatic neuroma without evidence of malignancy. Six months later, CT showed the same findings; a suspicious solid pancreatic mass surrounding the superior mesenteric and the celiac artery (Fig. 5). A new CT-guided biopsy was performed because of increasing CA 19-9 value (202 $\mathrm{U} / \mathrm{mL}$ ), which revealed a moderately differentiated recurrent cholangiocarcinoma. The patient received palliative radiochemotherapy as the lesion was judged unresectable. At the last follow-up, 60 months after the first diagnosis of cholangiocarcinoma, the patient was in a relatively good physical condition without any sing of distant metastases.

\section{Discussion}

Neuromas are likely benign proliferations of disorganized peripheral nerve fibers that are distinct from schwannoma and neurofibroma. They occur either after surgical trauma to nerve twigs (traumatic neuromas), in association with hereditary multitumor syndromes (mul- tiple endocrine neoplasia type II, PTEN-hamartoma syndrome, and other rare conditions), or as isolated sporadic lesions unassociated with trauma or other underlying disease $[6,7]$.

The first reported neuroma of the biliary tract was reported by Husseinoff [ 8 ] in 1928 , followed by Shapiro and Lifvendahl [9] in 1931. In both instances, the neuromas were located at the cystic duct stump and were post-mortem findings. The first neuroma of the bile ducts described in a clinical patient was reported by Comfort and Walters [10] in 1931. Since then, approximately 100 cases have been reported in the English literature $[2,3,11]$. Neuroma of the biliary tree is distinctly uncommon. They arise from the abundant network of sympathetic and parasympathetic nerve fibers in the wall of the gallbladder and bile ducts $[2,12]$. There is no gender predominance. Clinical manifestations are generally non-specific, and some of them represented an incidental finding during investigation for abnormal liver tests [13]. Symptomatic patients tend to present with intermittent right upper quadrant pain and jaundice $[10,14]$. Other rare clinical features include fever and pruritus. The majority of the reported cases involved the extrahepatic or common bile duct $(66 \%)[3,10,12-26]$ and the stump of the cystic duct $[6,8,9,11,27-30]$. In other cases, the neuromas involved the right hepatic duct [31], both intrahepatic and extrahepatic bile ducts $[2,16,32]$, the cystic duct [33] or the surrounding tissues (e.g., hepatoduodenal ligament [13] or biliodigestive anastomosis [17]). Rare unusual cases reported in the literature are neuromas arising in the gallbladder due to an unsuccessful cholecystectomy performed 20 years previously [34] and a bile duct neuroma that developed in a remnant choledochal cyst associated with total agenesis of the dorsal pancreas [35]. The current cases presented with obstructive jaundice as in most of reported cases, but 2 of them differed from the majority of reported cases in involvement of both the intra- and extrahepatic bile ducts and the absence of a relevant surgical history.

The vast majority of patients with biliary neuromas have a history of previous surgery such as cholecystectomy (53\%) or liver transplantation (27\%). Neuromas without history of antecedent surgery comprised $20 \%$ of the cases [24]. Many of these neuromas represented amputation or traumatic neuromas that developed at the cut end of the remnant cystic duct or in the wall of the bile duct $[11,17,18,20]$. In one study, bile duct neuroma has been demonstrated in up to $10 \%$ of all post-cholecystectomy patients at autopsy [32].

The majority occurred after cholecystectomy in the cystic duct stump presenting from several months [20] to 45 years [21] after surgery and have been described after both laparoscopic and open surgery [3, 21, 22], often combined with simultaneous choledochotomy. Excep- 
tionally, neuromas of the cystic duct stump presented with pain syndrome [27]. Traumatic neuromas of the biliary tree causing strictures have occasionally been described after liver transplantation, too [36]. Herrera et al. [23] reported 15 cases of traumatic neuromas that were detected between 1 and 17 months after transplantation (median: 4 months) either during surgery for obstructive jaundice (12 cases) or after alterations of liver function tests (2 cases), or incidentally discovered after retransplantation (1 case). It has been concluded that biliary stricture after orthotopic liver transplantation occurs in $3.5-10 \%$ of the cases $[4,23,30,36]$. Thus, they should be considered in the differential diagnosis of late biliary strictures after orthotopic liver transplantation. Neuromas were found in autopsies of $27.9 \%$ of the patients who died 3 months to 2 years after liver transplant, but only in 1 out of 26 cases did the lesion cause stenosis of the bile ducts [30].

The etiology of bile duct neuromas remains unclear, but various types of trauma during surgical procedures can initiate the development of a neuroma such as thermal [12] and mechanical injury or postoperative bile leakage [21] or prolonged irritation [22]. However, around $20 \%$ of the patients had no history of previous surgery, cholelithiasis, or other biliary diseases, who should be considered in a separate category $[24,33]$. The etiology of these neuromas should be further investigated. Spontaneous mucosal neuromas and involvement of the gallbladder by neurofibromatosis and ganglioneuromatosis have also been reported [24, 37, 38]. None of our patients had a history of neurofibromatosis or MEN2.

Imaging requires a CT scan and/or MRI to provide information on the location and the extent of the tumor and sometimes a specific diagnosis. Neuromas usually appear in CT as a homogenous mass with heterogeneous contrast enhancement and sometimes show secondary degeneration such as a cystic change, cavity formation, necrosis, or calcification. Dilatation of the biliary ducts is the most typical finding $[1,2,38,39]$, which was also demonstrated in our case. The MRI findings of neuromas show masses with low-signal intensity on the T1-weighted images and inhomogeneous high-signal intensity on the T2weighted images, as was found in the present case. It has also been reported that the signal intensity of the nerve tissue was the same as that of soft tissue and the pancreatic head, resulting in difficulty in detecting small traumatic neuromas of the biliary tree, especially if there is not enough fatty tissue around the bile duct [1,38-40]. Only a few reports have included the $\mathrm{CT}$ and $\mathrm{MR}$ imaging findings of traumatic neuroma $[12,38]$. Combining cholangioscopy and intraductal ultrasound with biopsy, the preoperative diagnosis of tumors of the extrahepatic bile duct can be improved substantially [21]. MRCP can reveal the level and extent of stenosis of the bile duct, as
ERCP [38]. We supported imaging of the extrahepatic biliary tree with ERCP and MRCP preoperatively; however, definitive diagnosis was not described based on imaging alone. However, despite the availability of modern imaging techniques, the preoperative diagnosis of neuroma is difficult, and in most cases the final diagnosis is made at surgery [39].

Our patient had an elevated CA 19-9 levels of 2,252 U/ $\mathrm{ml}$ (normal range <27) prior to surgery. CA 19-9 levels are often elevated with biliary tract carcinoma but also in benign diseases such as liver diseases, ascending cholangitis, and pancreatitis [41-43]. Other factors that were thought to help delineate malignant versus benign strictures of the biliary tree (total bilirubin $>75 \mu \mathrm{mol}$, greater stricture length, and the presence of intrahepatic biliary dilation) were all suggestive but not diagnostic for malignant biliary stricture [44].

The differential diagnosis of obstructive jaundice includes postinflammatory fibrosis, retained stones, postoperative scar stricture, bile duct carcinoma or cystadenoma, adenocarcinoma of pancreas and extrinsic compression $[9,43,45]$. Benign tumors of the biliary tree leading to obstructive jaundice are rare $[46,47]$.

Generally, non-surgical treatments including balloon dilatation, laser cautery, and stent placement are available for benign bile duct stenosis. However, the associated biliary obstruction, very severe fibrosis and pain are not treated well in the long term with these methods. Due to the need for biliary decompression and, in most cases, to obtain the correct diagnosis, surgery is indicated. The principal method of treatment in most publications and in our patient was segmental resection of the biliary tree harboring the neuroma with negative margins, periportal lymphadenectomy, subsequent Roux-en-Y reconstruction with hepaticojejunostomy and simultaneous cholecystectomy. Given that the diagnosis is almost never made preoperatively, and cholangiocarcinoma remains an important differential, a simple excision and hepaticojejunostomy may not be adequate and an aggressive resection with formal periportal lymphadenectomy is advocated, unless the diagnosis is definitively known preoperatively. Other methods, e.g. segmental resection of the common bile duct and suturing it over Kehr's drain, or resection of the distal part of the common bile duct and anastomosing it with the duodenum, are performed rarely [22]. In patients without a history of previous surgery as our patient, segmental stenosis of hepatic duct was caused by barely palpable thickening of the wall. Neuromas of biliary tree have an excellent prognosis after surgical resection, and there is no evidence to date that these tumors have a malignant potential $[6,42]$.

In conclusion, biliary tract neuromas are rare and mostly involve the extrahepatic bile ducts. Due to their non-specific clinical features, preoperative clinical diagnosis is only 
rarely rendered, and a preoperative imaging diagnosis is quite difficult, too, since neuromas have no characteristic features that would permit their detection using diagnostic imaging techniques, but the presence of a branching appearance along the course of the bile ducts is suggestive. These potentially curable tumors should be included in the differential diagnosis of tumors arising in the biliary system, in particular in patients with jaundice who had a previous cholecystectomy or other relevant surgical history. Biopsy is required for confirmation and to determine prognosis. An aggressive surgical approach may prove the only curative measure for definitive biliary decompression in some cases. Careful interpretation of clinical/histological findings is mandatory in patients with a previous biliary malignancy to avoid mistaking the benign neuroma as the sole disease, as illustrated by our third case.

\section{Statement of Ethics}

The approval of the Ethics Committee of the University Medical Faculty of Erlangen was obtained. All authors state that subjects have given their written informed consent to publish their case.

\section{Conflict of Interest Statement}

The authors have no conflicts of interest to declare.

\section{Funding Sources}

No funding was received.

\section{Author Contributions}

N.V. made the literature research, participated in the design of the study, collected and analyzed the data, wrote the manuscript, and critically evaluated the manuscript. A.P. participated in the design of the study and critically evaluated the manuscript. A.S. participated in the design of the study and critically evaluated the manuscript. R.S.C. participated in the design of the study and critically evaluated the manuscript. R.G. participated in the design of the study, assisted in drafting the manuscript, and critically evaluated the manuscript. A.A. participated in the design of the study, assisted in drafting the manuscript, and critically evaluated the manuscript. All authors read and approved the final manuscript.

\section{References}

1 Levy AD, Murakata LA, Abbott RM, Rohrmann CA Jr; Armed Forces Institute of Pathology. From the archives of the AFIP. Benign tumors and tumorlike lesions of the gallbladder and extrahepatic bile ducts: radiologic-pathologic correlation. Radiographics. 2002 Mar-Apr;22(2):387-413.

2 Hotta T, Kobayashi Y, Taniguchi K, Naka T, Johata K, Sahara M, et al. A traumatic neuroma of the bile duct: a case report. Hepatogastroenterology. 2004 Jan-Feb;51(55):3942.

3 Ueno Y, Ikeda K, Maehara M, Sakaida N, Omura N, Kurokawa H, et al. Traumatic neuroma of the bile duct. Abdom Imaging. 2008 Sep-Oct;33(5):560-2.

4 Terzi A, Kirnap M, Sercan C, Ozdemir G, Ozdemir BH, Haberal M. Traumatic neuroma causing biliary stricture after orthotopic liver transplant, treated with hepaticojejunostomy: a case report. Exp Clin Transplant. 2017 Feb; 15 Suppl 1:175-7.

5 Northover JM, Terblanche J. A new look at the arterial supply of the bile duct in man and its surgical implications. Br J Surg. 1979 Jun; 66(6):379-84

6 Berge T, Haeger K. Clinical significance of the amputation neuroma and length of the cystic duct remnant. Acta Chir Scand. 1967;133(1): 55-60.

7 Bürrig KF, Torsello G. [Scar neuroma following cholecystectomy. Differential diagnostic aspects and review of the literature]. Pathologe. 1985 Nov;6(6):319-22.

8 Husseinoff D. Ueber einen Fall von Wucherung des Nervengewebes nach wiederholten Operationen der Gallengaenge. Zbl Allg Path. $1928 ; 43: 344-8$.
9 Shapiro PF, Lifvendahl RA. Tumors of the extrahepatic bile-ducts. Ann Surg. 1931 Jul; 94(1):61-79.

10 Comfort MW, Walters W. Intermittent jaundice due to neuroma of cystic and common bile ducts. Ann Surg. 1931 Jun;93(6):1142-5.

11 Cattell RB, St Ville J. Amputation neuromas of the biliary tract. Arch Surg. 1961 Aug; 83(2):242-6.

12 Nagafuchi Y, Katuki M, Hisatome K, Higure A, Asami S, Itoh H. A traumatic neuroma associated with obstructive jaundice after laparoscopic cholecystectomy. Hepatogastroenterology. 1998 Mar-Apr;45(20):424-7.

13 Oden B. Neurinoma of the common bile duct; report of a case. Acta Chir Scand. 1955 Jan; 108(5):393-7.

14 Wysocki A, Papla B, Budzyński P. Neuromas of the extrahepatic bile ducts as a cause of obstructive jaundice. Eur J Gastroenterol Hepatol. 2002 May;14(5):573-6.

15 Shumate CR, Curley SA, Cleary KR, Ames FC. Traumatic neuroma of the bile duct causing cholangitis and atrophy of the right hepatic lobe. South Med J. 1992 Apr;85(4):425-7.

16 Larson DM, Storsteen KA. Traumatic neuroma of the bile ducts with intrahepatic extension causing obstructive jaundice. Hum Pathol. 1984 Mar;15(3):287-9.

17 van Gulik TM, Brummelkamp WH, Lygidakis NJ. Traumatic neuroma giving rise to biliary obstruction after reconstructive surgery for iatrogenic lesions of the biliary tract-a report of three cases. Hepatogastroenterology. 1989 Aug;36(4):255-7.
18 Paquette IM, Suriawinata AA, Ornvold K, Gardner TB, Axelrod DA. Neuroma of the bile duct: a late complication after cholecystectomy. J Gastrointest Surg. 2009 Aug;13(8): 1517-9.

19 Cieslak AK, Stout AP. Traumatic and amputation neuromas. Arch Surg. 1946 Dec;53(6): 646-51.

20 Watanabe O, Haga S, Okabe T, Kumazawa K, Shiozawa S, Tsuchiya A, et al. Amputation neuroma of common bile duct with obstructive jaundice. J Gastroenterol Hepatol. 2001 Aug;16(8):945-6.

21 Nagata Y, Tomioka T, Chiba K, Kanematsu T. Traumatic neuroma of the common hepatic duct after laparoscopic cholecystectomy. Am J Gastroenterol. 1995 Oct;90(10):1887-8.

22 Rush BF Jr, Stefaniwsky AB, Sasso A, Dumitrescu I, Wexler D. Neuroma of the common bile duct. J Surg Oncol. 1988 Sep;39(1):17-21.

23 Herrera L, Martino E, Rodríguez-Sanjuán JC, Castillo J, Casafont F, González F, et al. Traumatic neuroma of extrahepatic bile ducts after orthotopic liver transplantation. Transplant Proc. 2009 Apr;41(3):1054-6.

24 Sugahara K, Yamamoto M, lizuka H, Yoshioka M, Miura K. Spontaneous neuroma of the bile duct: a case report. Am J Gastroenterol. 1985 Oct;80(10):807-9.

25 Katsinelos P, Dimiropoulos S, Galanis I, Tsolkas P, Paroutoglu G, Arvaniti M, et al. Biliary stricture due to neuroma after an innocent blunt abdominal trauma. Surg Endosc. 2002 Oct;16(10):1494.

26 Cheng Y, Jia Q, Xiong X, Cheng N. Traumatic bile duct neuroma developing in a remnant choledochal cyst. Dig Liver Dis. 2014 May; 46(5):e3. 
27 Prinz RA, Greenlee HB, Caporale FS. Amputation neuroma of the cystic duct: a treatable cause of postcholecystectomy pain. Am Surg. 1979 Aug;45(8):543-4.

28 Joske RA, Finlay-Jones LR. Amputation neuroma of the cystic-duct stump. Br J Surg. 1966 Sep;53(9):766-8.

29 Troppoli DV, Cella LJ Jr. The postcholecystectomy syndrome. Ann Surg. 1953 Feb; 137(2):250-4.

30 Colina F, García-Prats MD, Moreno E, García-Muñoz H, Ballestín C, Mayordomo JI, et al. Amputation neuroma of the hepatic hilum after orthotopic liver transplantation. Histopathology. 1994 Aug;25(2):151-7.

31 Chantranuwat C, Shuangshoti S. Traumatic neuroma as a cause of obstructive jaundice. Med Assoc Thai. 1999 Jun;82(6):619-22.

32 Pickens A, Vickers SM, Brown KL, Reddy VV, Thompson JA. An unusual etiology of biliary hilar obstruction and the potential role of acidic fibroblast growth factor in the development of a biliary neuroma. Am Surg. 1999 Jan; 65(1):47-51.

33 Peison B, Benisch B. Traumatic neuroma of the cystic duct in the absence of previous surgery. Hum Pathol. 1985 Nov;16(11):1168-9.

34 Sano T, Hirose T, Kagawa N, Hizawa K, Saito K. Polypoid traumatic neuroma of the gallbladder. Arch Pathol Lab Med. 1985 Jun; 109(6):574-6.
35 Otani T, Shioiri T, Mishima H, Ishihara A, Maeshiro T, Matsuo A, et al. Bile duct schwannoma developed in the remnant choledochal cyst-a case associated with total agenesis of the dorsal pancreas. Dig Liver Dis. 2005 Sep; 37(9):705-8.

36 Navez J, Golse N, Bancel B, Rode A, Ducerf C, Mezoughi S, et al. Traumatic biliary neuroma after orthotopic liver transplantation: a possible cause of "unexplained" anastomotic biliary stricture. Clin Transplant. 2016 Oct; 30(10):1366-9.

37 Albores-Saavedra J, Henson DE, Klimstra DS. Benign nonepithelial and neurogenic, malignant mesenchymal, and miscellaneous malignant tumors of gallbladder. In: Rosai J, Sobin LH, editors. Tumors of the gallbladder, extrahepatic bile ducts, and ampulla of Vater. Atlas of tumor pathology, 3rd series, fascicle 27. Washington (DC): Armed Forces Institute of Pathology; 2000. pp. 123-42.

38 Tsitouridis J, Kouklakis G, Xiarhos P, Patakiuta F. Non traumatic neuroma of the bile duct: report of a case. Dig Endosc. 1998 Oct; 10(4):323-6.

39 Kim HH, Koh YS, Seoung JS, Hur YH, Cho CK. Education and imaging. Hepatobiliary and pancreatic: traumatic bile duct neuroma. J Gastroenterol Hepatol. 2011 Sep;26(9):1465.

40 Boutin RD, Pathria MN, Resnick D. Disorders in the stumps of amputee patients: MR imaging. AJR Am J Roentgenol. 1998 Aug; 171(2):497-501.
41 Mann DV, Edwards R, Ho S, Lau WY, Glazer G. Elevated tumour marker CA19-9: clinical interpretation and influence of obstructive jaundice. Eur J Surg Oncol. 2000 Aug;26(5): 474-9.

42 Hyman J, Wilczynski SP, Schwarz RE. Extrahepatic bile duct stricture and elevated CA 199: malignant or benign? South Med J. 2003 Jan;96(1):89-92.

43 Elkhatib I, Shah N, Savides TJ. Neuroma of the bile duct mimicking cholangiocarcinoma. Gastrointest Endosc. 2017 May;85(5):1100-1.

44 Bain VG, Abraham N, Jhangri GS, Alexander TW, Henning RC, Hoskinson ME, et al. Prospective study of biliary strictures to determine the predictors of malignancy. Can J Gastroenterol. 2000 May;14(5):397-402.

45 Gerhards MF, Vos P, van Gulik TM, Rauws EA, Bosma A, Gouma DJ. Incidence of benign lesions in patients resected for suspicious hilar obstruction. Br J Surg. 2001 Jan;88(1):4851.

46 Verbeek PC, van Leeuwen DJ, de Wit LT, Reeders JW, Smits NJ, Bosma A, et al. Benign fibrosing disease at the hepatic confluence mimicking Klatskin tumors. Surgery. 1992 Nov;112(5):866-71.

47 Dowdy GS Jr, Olin WG Jr, Shelton EL Jr, Waldron GW. Benign tumors of the extrahepatic bile ducts. Report of three cases and review of the literature. Arch Surg. 1962 Sep;85(3):50313. 